\title{
A silver-manganese dual co-catalyst for selective reduction of carbon dioxide into carbon monoxide over a potassium hexatitanate photocatalyst with water
}

\section{AUTHOR(S):}

Zhu, Xing; Yamamoto, Akira; Imai, Shota; Tanaka, Atsuhiro; Kominami, Hiroshi; Yoshida, Hisao

\section{CITATION:}

Zhu, Xing ... [et al]. A silver-manganese dual co-catalyst for selective reduction of carbon dioxide into carbon monoxide over a potassium hexatitanate photocatalyst with water. Chemical Communications 2019, 90: 13514-13517

\section{ISSUE DATE:}

2019-11-21

URL:

http://hdl.handle.net/2433/253738

\section{RIGHT:}

This is the accepted manuscript of the article, which has been published in final form at

https://doi.org/10.1039/c9cc06038c.; The full-text file will be made open to the public on 28 September 2020 in

accordance with publisher's 'Terms and Conditions for Self-Archiving'; この論文は出版社版でありません。引用の際に

は出版社版をご確認じ利用ください。; This is not the published version. Please cite only the published version. 


\section{COMMUNICATION}

Received 00th January 20xx Accepted 00th January 20xx DOI: $10.1039 / x 0 \times x 00000 x$

\section{A silver-manganese dual cocatalyst for selective reduction of carbon dioxide into carbon monoxide over a potassium hexatitanate photocatalyst with watert}

\author{
Xing Zhu, ${ }^{a}$ Akira Yamamoto, ${ }^{\mathrm{a}, \mathrm{b}}$ Shota Imai, ${ }^{\mathrm{c}}$ Atsuhiro Tanaka, ${ }^{\mathrm{d}, \mathrm{e}}$ Hiroshi Kominami, ${ }^{\mathrm{d}}$ and Hisao \\ Yoshida ${ }^{\mathrm{a}, \mathrm{b} *}$
}

\begin{abstract}
A Ag-Mn dual cocatalyst deposited on a $\mathrm{K}_{2} \mathrm{Ti}_{6} \mathrm{O}_{13}$ photocatalyst significantly enhances photocatalytic $\mathrm{CO}_{2}$ reduction into $\mathrm{CO}$ by water with extremely high selectivity such as $98 \%$ by using $\mathrm{H}_{2} \mathrm{O}$ as an electron donor, owing to the properties of $\mathrm{Ag}$ and $\mathrm{MnO}_{\mathrm{x}}$ species for promoting $\mathrm{CO}$ and $\mathrm{O}_{2}$ formation, respectively.
\end{abstract}

In recent years, the photocatalytic reduction of $\mathrm{CO}_{2}$ with water into useful compounds has been widely studied to achieve less $\mathrm{CO}_{2}$ emission for global environmental issues and utilization of $\mathrm{CO}_{2}$ as a carbon source. Various heterogeneous photocatalysts have been reported for the reduction of $\mathrm{CO}_{2}$ with water to produce formate, $\mathrm{CO}$, $\mathrm{CH}_{3} \mathrm{OH}$, and $\mathrm{CH}_{4} \cdot{ }^{1}$ Among these possible reductive products from $\mathrm{CO}_{2}$, the most useful product would be $\mathrm{CO}$ since it is a valuable chemical intermediate for further chemical syntheses and easily separable from the aqueous reaction media to the gas phase.

In the typical photocatalytic $\mathrm{CO}_{2}$ reduction system in aqueous solution, two reactions competitively can occur, i.e., photocatalytic reduction of $\mathrm{CO}_{2}$ to form $\mathrm{CO}$ and photocatalytic water splitting into $\mathrm{H}_{2}$ and $\mathrm{O}_{2}$, where the reductive products are $\mathrm{CO}$ and $\mathrm{H}_{2}$, respectively, and the common oxidative product is $\mathrm{O}_{2}{ }^{2}$

But, the redox potential of $\mathrm{H}^{+} / \mathrm{H}_{2}$ is more positive than that of $\mathrm{CO}_{2} / \mathrm{CO}$, so the reduction of protons $\left(\mathrm{H}^{+}\right)$to $\mathrm{H}_{2}$ is thermodynamically easier than that of $\mathrm{CO}_{2}$ to $\mathrm{CO}$. Thus, it seems especially challenging to reduce only $\mathrm{CO}_{2}$ molecules selectively in an aqueous solution in principle. Recently, it was discovered that deposited $\mathrm{Ag}$

\footnotetext{
a. Graduate School of Human and Environmental Studies, Kyoto University, Kyoto 606-8501, Japan. Email: yoshida.hisao.2a@kyoto-u.ac.jp.

b. Elements Strategy Initiative for Catalysts and Batteries (ESICB), Kyoto University, Kyoto615-8520, Japan. Email: yoshida.hisao.2a@kyoto-u.ac.jp.

Molecular and Material Engineering, Interdisciplinary Graduate School of Science and Engineering, Kindai University, 3-4-1 Kowakae, Higashiosaka, Osaka 577 8502, Japan.

d. Department of Applied Chemistry, Faculty of Science and Engineering Kindai University, 3-4-1 Kowakae, Higashiosaka, Osaka 577-8502, Japan.

e. Precursory Research for Embryonic Science and Technology (PRESTO), Japan

Science and Technology Agency (JST), 4-1-8 Honcho, Kawaguchi 332-0012, Japan

+ Electronic Supplementary Information (ESI) available: Experimental and results

(characterization and photocatalytic activity tests). See DOI: 10.1039/x0xx00000x
}

nanoparticles could function as the active cocatalyst for $\mathrm{CO}_{2}$ reduction to form $\mathrm{CO}^{2}$ Recently, many kinds of Ag-modified photocatalysts to produce $\mathrm{CO}, \mathrm{H}_{2}$ and $\mathrm{O}_{2}$ have been reported, such as $\mathrm{Ag} / \mathrm{BaLa}_{4} \mathrm{Ti}_{4} \mathrm{O}_{15},{ }^{2} \mathrm{Ag} / \mathrm{Ga}_{2} \mathrm{O}_{3},{ }^{3} \mathrm{Ag} / \mathrm{La}_{2} \mathrm{Ti}_{2} \mathrm{O}_{7},{ }^{4}$ and so on. ${ }^{5}$ Although some developed photocatalysts exhibited high activity or high selectivity for the $\mathrm{CO}_{2}$ reduction, ${ }^{6}$ the efficiency has not been high enough to put into practice still now. As for the selectivity toward CO evolution, although it was less than $70 \%$ several years ago, ${ }^{2}$ it has become higher such as $94 \%$ with $\mathrm{Ag} / \mathrm{CaTiO}_{3}{ }^{7}$ and $96 \%$ over $\mathrm{Ag} / \mathrm{SrNb}_{2} \mathrm{O}_{6}{ }^{8}$ quite recently. It is noted that, in some cases, as was discussed in our previous paper, ${ }^{9}$ the $\mathrm{O}_{2}$ evolution was not always stoichiometric both in water splitting and $\mathrm{CO}_{2}$ reduction. Many reported papers had proposed the possible reasons for the nonstoichiometric formation of $\mathrm{O}_{2}$, such as high overpotential required for $\mathrm{O}_{2}$ evolution and some side reactions. ${ }^{9,10}$ And it has also been reported that some metal oxides (such as $\mathrm{IrO}_{2}, \mathrm{RuO}_{2}, \mathrm{CoO}_{x}$, $\mathrm{MnO}_{\mathrm{x}}$, etc.) can act as the water oxidation cocatalyst for water splitting but rarely for $\mathrm{CO}_{2}$ reduction so far. ${ }^{11}$

In these years, some dual cocatalysts with proper structures including core-shell type and two separated metal/oxide particles, such as $\mathrm{Ag} / \mathrm{Cu},{ }^{12} \mathrm{Pt} / \mathrm{Cu}_{2} \mathrm{O},{ }^{13} \mathrm{Ag} / \mathrm{CrO}_{x},{ }^{14}$ and $\mathrm{Cr} / \mathrm{Rh}^{15}$ have been proved to enhance the activity of $\mathrm{CO}_{2}$ conversion or water splitting by taking advantage of the synergistic function of dual active sites for both reductive and oxidative reactions simultaneously, or the modification of the cocatalyst surface suppressing the backward reaction. ${ }^{14-16}$ Recently, a combination of $\mathrm{Ag}$ and $\mathrm{Mn}$ was examined as a dual cocatalyst deposited on $\mathrm{TiO}_{2}$ photocatalyst to promote $\mathrm{CO}$ formation from a mixture of $\mathrm{NaHCO}_{3}$ and $\mathrm{H}_{2} \mathrm{SO}_{4}$ in an aqueous solution although $\mathrm{O}_{2}$ evolution and selectivity toward $\mathrm{CO}$ evolution were not clearly mentioned. ${ }^{17}$

In the present study, we examined potassium hexatitanate $\left(\mathrm{K}_{2} \mathrm{Ti}_{6} \mathrm{O}_{13}\right.$, referred to as $\left.\mathrm{KTO}\right)$, which is one of the well-known functional materials with wide applications in many fields such as, electrochemistry, ${ }^{18}$ ion exchange, ${ }^{19}$ and photocatalyst, ${ }^{20}$ and has been modified with each typical cocatalyst to be studied as a photocatalyst for steam reforming of methane, ${ }^{20 a}$ water splitting, ${ }^{20 b, c}$ and dye degradation. ${ }^{20 d}$ Here, we found for the first 
time that deposition of a Ag-Mn dual cocatalyst on a KTO photocatalyst can much improve the photocatalytic $\mathrm{CO}_{2}$ reduction into $\mathrm{CO}$ by using $\mathrm{H}_{2} \mathrm{O}$ as an electron donor with very high $\mathrm{CO}$ selectivity of $98 \%$ among the reductive products.

A KTO sample was fabricated by a flux method, as mentioned in ESIt. The crystal structure of $\mathrm{K}_{2} \mathrm{Ti}_{6} \mathrm{O}_{13}$ and its purity was confirmed by XRD (Fig. S2, ESI + ). The SEM image revealed that the samples consisted of rod-like crystals (Fig. S3, ESI + ), confirming that the molten salt flux can enhance the crystallization and regulate the crystal growth of each facet to form the unique hexagonal rod-like morphology of alkali hexatitanates. ${ }^{20 \mathrm{~b}}$ The bandgap of the bare KTO was estimated to be $3.56 \mathrm{eV}$ by a diffuse reflectance (DR) UV-visible spectrum and the Davis-Mott equation. ${ }^{21}$

A cocatalyst consisting of one or two components was loaded on the KTO sample by a photodeposition (PD) method (See ESI + ). ${ }^{14}$ The loading amount of cocatalyst was determined by XRF. Even if the desired amount of the source compound was used, the actually loaded amount of cocatalyst was much less than the desired value for some elements such as $\mathrm{Cr}, \mathrm{Mn}, \mathrm{Co}$, and $\mathrm{Ni}$, which would be very sensitive to the conditions. The samples are referred to as $\operatorname{Ag}(x)$ $\mathrm{M}(y) / \mathrm{KTO}$, where $x$ and $y$ mean the actual loading amount of Ag and $M(w t \%)$ determined by XRF.

The photocatalytic activity test for $\mathrm{CO}_{2}$ reduction with water was carried out using a $\mathrm{CO}_{2}$ bubbling flow reaction system (Fig. $\mathrm{S} 1, \mathrm{ESI}+$ ) as mentioned in ESIt. In most cases, $\mathrm{CO}, \mathrm{H}_{2}$ and $\mathrm{O}_{2}$ were produced under photoirradiation. Since no other reductive products than $\mathrm{CO}$ and $\mathrm{H}_{2}$ were observed, the selectivity toward $\mathrm{CO}$ evolution, $\mathrm{S}_{\mathrm{co}}(\%)=$ $100 \times R_{\mathrm{CO}} /\left(R_{\mathrm{CO}}+R_{\mathrm{H} 2}\right)$, and the ratio of the consumed electron and hole, $R\left(\mathrm{e}^{-} / \mathrm{h}^{+}\right)=\left(R_{\mathrm{CO}}+R_{\mathrm{H} 2}\right) / 2 R_{\mathrm{O} 2}$, were calculated, ${ }^{22}$ where $R_{\mathrm{CO}}, R_{\mathrm{H} 2}$, and $R_{O 2}$ present the production rate of $\mathrm{CO}, \mathrm{H}_{2}$, and $\mathrm{O}_{2}$, respectively.

The results of photocatalytic reaction tests over eight samples loaded with different cocatalysts were shown in Fig. S4. Among them, only the $\mathrm{Ag}(1.0)-\mathrm{Mn}(0.09) / \mathrm{KTO}$ sample exhibited higher $\mathrm{CO}$ formation rate than the $\mathrm{Ag}(1.0) / \mathrm{KTO}$ sample, with the highest selectivity $\left(S_{\mathrm{CO}}=97.2 \%\right)$.

According to the optimization of the $\mathrm{Ag}$ and $\mathrm{Mn}$ loading amount (Fig. S5 and S6, ESI + ), it was found that the optimum loading amounts were in the range of $0.5-2.0 \mathrm{wt} \%$ for $\mathrm{Ag}$ and $0.10-0.13 \mathrm{wt} \%$ for $\mathrm{Mn}$, and the $\mathrm{Ag}(1.0)-\mathrm{Mn}(0.12) / \mathrm{KTO}$ sample exhibited the highest $\mathrm{CO}$ production rate $\left(10.6 \mu \mathrm{mol} \mathrm{h}^{-1}\right)$ with very high selectivity $\left(S_{\mathrm{CO}}=98.2 \%\right)$. It is noted that the selectivity toward $\mathrm{CO}$ evolution was the highest among the published data so far.

Further, the $\mathrm{Ag}(0.5)-\mathrm{Mn}(0.13) / \mathrm{KTO}$ sample realized an efficient $\mathrm{O}_{2}$ evolution giving an almost ideal redaction/oxidation products ratio with high activity (Fig. S5, ESI+). Fig. 1 shows a time course of the reaction test with the $\mathrm{Ag}(0.5)-\mathrm{Mn}(0.13) / \mathrm{KTO}$ sample. The initial high production rate of $\mathrm{CO}$ would originate from the initial state of welldispersed Ag cocatalyst particles. ${ }^{5 \mathrm{~d}}$ Although the $\mathrm{O}_{2}$ evolution was insufficient in the induction period, which may be due to photoadsorption of $\mathrm{O}_{2}$ on the photocatalyst surface or some competitive side reactions. ${ }^{9,10}$ But it gradually increased with irradiation time and the stoichiometric production of $\mathrm{CO}$ and $\mathrm{O}_{2}$ was continuously observed for 24 hours, revealing the equivalent consumption of photoexcited electrons and holes, i.e. $R\left(\mathrm{e}^{-} / \mathrm{h}^{+}\right)=1.1$.
The blank tests confirmed that the $\mathrm{CO}$ molecules predominantly originated from molecular $\mathrm{CO}_{2}$ (Table $\mathrm{S} 1, \mathrm{ESI}+$ ). Based on these results, it was proved that the dual Ag-Mn cocatalyst could enhance the photocatalytic $\mathrm{CO}_{2}$ reduction to $\mathrm{CO}$.

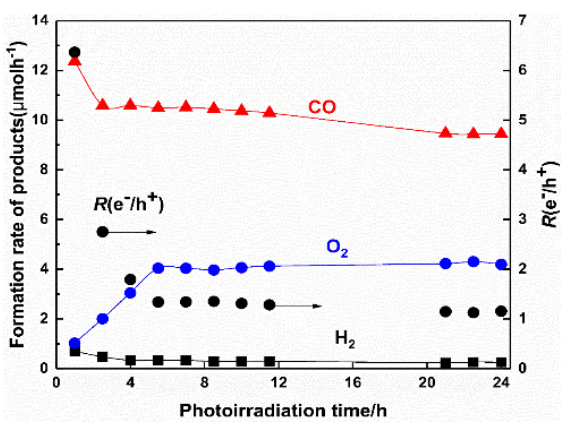

Fig. 1 Time course of the production rates of $\mathrm{CO}, \mathrm{H}_{2}$, and $\mathrm{O}_{2}$, and $R\left(\mathrm{e}^{-} / \mathrm{h}^{+}\right)$with the $\mathrm{Ag}(0.5)-\mathrm{Mn}(0.13) / \mathrm{KTO}$ sample in the photocatalytic $\mathrm{CO}_{2}$ reduction test.

To clarify the effects and roles of the Ag-Mn dual cocatalyst, four samples, the bare $\mathrm{KTO}, \mathrm{Mn} / \mathrm{KTO}, \mathrm{Ag} / \mathrm{KTO}$, and $\mathrm{Ag}-\mathrm{Mn} / \mathrm{KTO}$ samples, were examined as follows. As for the photocatalytic activity (Fig. 2), the $\mathrm{Mn}(0.15) / \mathrm{KTO}$ sample exhibited similar or lower activity to produce both $\mathrm{CO}$ and $\mathrm{H}_{2}$ compared with the bare KTO sample, demonstrating that the $\mathrm{Mn}$ cocatalyst cannot work solely. On the other hand, the formation rate of $\mathrm{CO}$ was strongly enhanced by loading the Ag cocatalyst and further improved with the Ag-Mn dual cocatalyst, confirming the obvious contribution of $\mathrm{Ag}$ cocatalyst and the further contribution of the dual cocatalyst for the $\mathrm{CO}_{2}$ reduction. The $\mathrm{CO}$ evolution rate with the $\mathrm{Ag}(1.0)-\mathrm{Mn}(0.12) / \mathrm{KTO}$ sample was 42 times higher than those with both the bare KTO and $\mathrm{Mn}(0.15) / \mathrm{KTO}$ samples, and almost 2 times higher than that with the $\mathrm{Ag}(1.0) / \mathrm{KTO}$ sample. The stability and durability of the sample were repeatedly confirmed for two times under the same condition (Fig. 1 and S7, $\mathrm{ESI}+$ ).

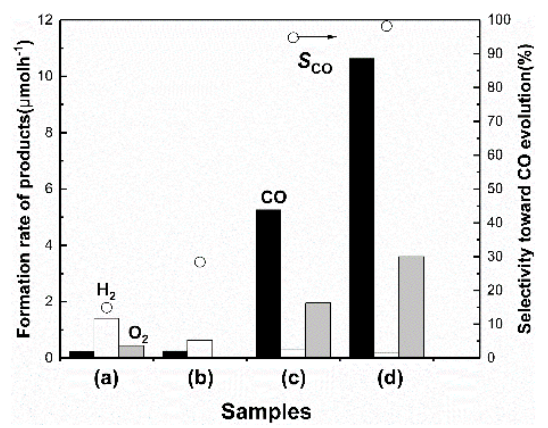

Fig. 2 Formation rate of products in the photocatalytic $\mathrm{CO}_{2}$ reduction with $\mathrm{H}_{2} \mathrm{O}$ over the various samples; (a) KTO, (b) $\mathrm{Mn}(0.15) / \mathrm{KTO}$, (c) $\mathrm{Ag}(1.0) / \mathrm{KTO}$, and (d) $\mathrm{Ag}(1.0)$ $\mathrm{Mn}(0.12) / \mathrm{KTO}$. Photocatalyst: $0.3 \mathrm{~g}$, reaction solution volume: $0.4 \mathrm{~L}$, additive: $0.5 \mathrm{M} \mathrm{NaHCO}_{3}, \mathrm{CO}_{2}$ flow rate: 30 $\mathrm{mL} \mathrm{min}{ }^{-1}$, light source: a $100 \mathrm{~W}$ high pressure Hg lamp.

DR UV-visible spectra of these samples are shown in Fig. S8 (ESI + ). Both the $\mathrm{Ag}(1.0) / \mathrm{KTO}$ sample and the $\mathrm{Ag}(1.0)-\mathrm{Mn}(0.09) / \mathrm{KTO}$ sample (Fig. S8c and S8d, ESI+) showed clearly a large broad band assignable to localized surface plasmon resonance (LSPR) of Ag nanoparticles at almost the same position around the $530 \mathrm{~nm}$, suggesting that $\mathrm{Ag}$ 
nanoparticles were present on the KTO surface, and they would be almost similar state irrespective of the presence of the $\mathrm{Mn}$ species.

The state and local structure of the dual cocatalyst were investigated by using $X$-ray absorption fine structure (XAFS). Fig. $3 \mathrm{~A}$ shows $\mathrm{Ag} \mathrm{K}$-edge $\mathrm{X}$-ray absorption near edge structures (XANES) of the prepared samples and two reference samples. The absorption edges $(25519 \mathrm{eV})$ in the spectra of the photocatalyst samples were consistent with that of $\mathrm{Ag}$ foil (25519 eV) but different from that of $\mathrm{Ag}_{2} \mathrm{O}(25521 \mathrm{eV})$, and the spectral feature of XANES for the photocatalyst samples is similar to that for Ag foil. The Fourier transforms of EXAFS spectra also showed almost the same feature for the photocatalyst samples and Ag foil (Fig. S9, ESI+). These facts indicate that the $\mathrm{Ag}$ species loaded on the surface of both the $\mathrm{Ag}(1.0) / \mathrm{KTO}$ and $\mathrm{Ag}(1.0)-\mathrm{Mn}(0.09) / \mathrm{KTO}$ samples were metallic. Thus, it was revealed that the coexistence of $\mathrm{Mn}$ species did not vary the metallic state of $\mathrm{Ag}$ cocatalyst.

Fig. 3B shows Mn K-edge XANES of the prepared samples and some reference compounds such as $\mathrm{Mn}$ foil, $\mathrm{MnO}, \mathrm{Mn}_{2} \mathrm{O}_{3}$, and $\mathrm{MnO}_{2}$. The absorption edges for the prepared samples were not strictly consistent with those for the references, meaning that the $\mathrm{Mn}$ species deposited on the photocatalyst samples had different local structures from these typical manganese oxides. In detail, the edge position of the spectra for the $\mathrm{Ag}(1.0)$ $\mathrm{Mn}(0.09) / \mathrm{KTO}$ and $\mathrm{Mn}(0.15) / \mathrm{KTO}$ samples (Fig. 3Be and 3Bf) were close to that for $\mathrm{Mn}_{2} \mathrm{O}_{3}$ (Fig. 3BC). However, the main peak position for the two samples was close to that for MnO (Fig. $3 \mathrm{Bb}$ ) and the second peak at the post edge for the $\mathrm{Mn}(0.15) / K T O$ sample was close to that for the main peak for $\mathrm{MnO}_{2}$ (Fig. 3Bd). The Fourier transforms of EXAFS spectra of the photocatalyst samples also showed different features from those of the reference oxides (Fig. S10, ESI + ). Thus, the Mn species deposited on the KTO surface would have the unique local structures, suggesting that they are not aggregated as a single phase of manganese oxide particles but well dispersed on the surface with unique local structure and valences.
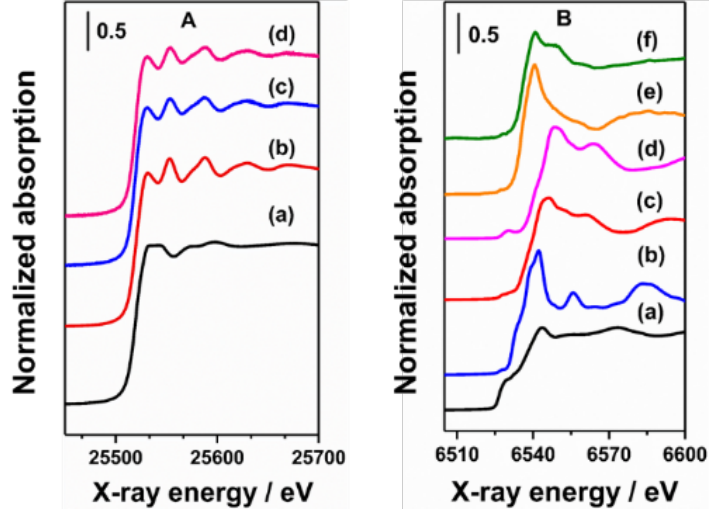

Fig. 3 [A] Ag K-edge XANES of (a) $\mathrm{Ag}_{2} \mathrm{O}$, (b) Ag foil, (c) $\mathrm{Ag}(1.0) / \mathrm{KTO}$, and (d) $\mathrm{Ag}(1.0)-\mathrm{Mn}(0.09) / \mathrm{KTO}$, and [B] Mn K-edge XANES of (a) Mn foil, (b) $\mathrm{MnO}$, (c) $\mathrm{Mn}_{2} \mathrm{O}_{3}$, (d) $\mathrm{MnO}_{2}$, (e) $\mathrm{Ag}(1.0)-\mathrm{Mn}(0.09) / \mathrm{KTO}$, and (f) $\mathrm{Mn}(0.15) / \mathrm{KTO}$

SEM images of the $\mathrm{Ag}(1.0) / \mathrm{KTO}$ and $\mathrm{Ag}(1.0)-\mathrm{Mn}(0.12) / \mathrm{KTO}$ samples show the presence of additional particles on the KTO crystals, although it is difficult to distinguish the $\mathrm{Ag}$ and $\mathrm{Mn}$ species on the latter sample (Fig. S11, ESI + ). TEM images of the above four samples were shown in Fig. 4. Comparing the $\mathrm{Mn}(0.15) /$ KTO sample (Fig. 4b) with the bare KTO sample (Fig. 4a), no nanoparticles were found to deposit on the surface of the KTO sample, and no Mn species were detected by EDS mapping due to the extremely low loading amount. However, as mentioned above, it was believed that the $\mathrm{Mn}$ species were well dispersed on the surface. For the $\mathrm{Ag}(1.0) / \mathrm{KTO}$ sample (Fig. 4c and $4 \mathrm{c}^{\prime}$ ) and the $\mathrm{Ag}(1.0)-\mathrm{Mn}(0.12) / \mathrm{KTO}$ sample (Fig. $4 \mathrm{~d}$ and $4 \mathrm{~d}^{\prime}$ ), Ag nanoparticles with the size less than $20 \mathrm{~nm}$ were observed and proved by the EDS mapping (Fig. S12, ESI+). The presence of $\mathrm{Mn}$ species was not confirmed also on the $\mathrm{Ag}(1.0)$ $\mathrm{Mn}(0.09) /$ KTO sample.

Finally, to clarify the role of the $\mathrm{MnO}_{\mathrm{x}}$ species, the photocatalytic tests of $\mathrm{O}_{2}$ evolution from an aqueous solution of $\mathrm{Ag}\left(\mathrm{NO}_{3}\right)$ were conducted. Compared with the bare KTO and $\mathrm{Ag}(0.5) / \mathrm{KTO}$ samples, the $\mathrm{Mn}(0.15) / \mathrm{KTO}$ and $\mathrm{Ag}(0.5)-$ $\mathrm{Mn}(0.13) /$ KTO samples exhibited larger amount of $\mathrm{O}_{2}$ evolutions with higher rates, especially the $\mathrm{Mn}(0.15) / \mathrm{KTO}$ sample did as shown in Fig. 5, even though the loading amount of the $\mathrm{Mn}$ species was very low. Here, it was clearly evidenced that the $\mathrm{Mn}$ species is beneficial to the $\mathrm{O}_{2}$ evolution, which is supported by literatures. ${ }^{23}$ In the present result, the photocatalyst with a $\mathrm{Ag}-\mathrm{Mn}$ dual cocatalyst exhibited the highest activity for photocatalytic $\mathrm{CO}_{2}$ reduction, while it showed lower activity than the photocatalyst with a single $\mathrm{Mn}$ cocatalyst for the oxygen evolution test, meaning that the addition of Ag nanoparticles seems to decrease the oxidative activity. A part of Ag species loaded on the oxidative sites may react with holes competitively or change the state of the $\mathrm{MnO}_{x}$ species.
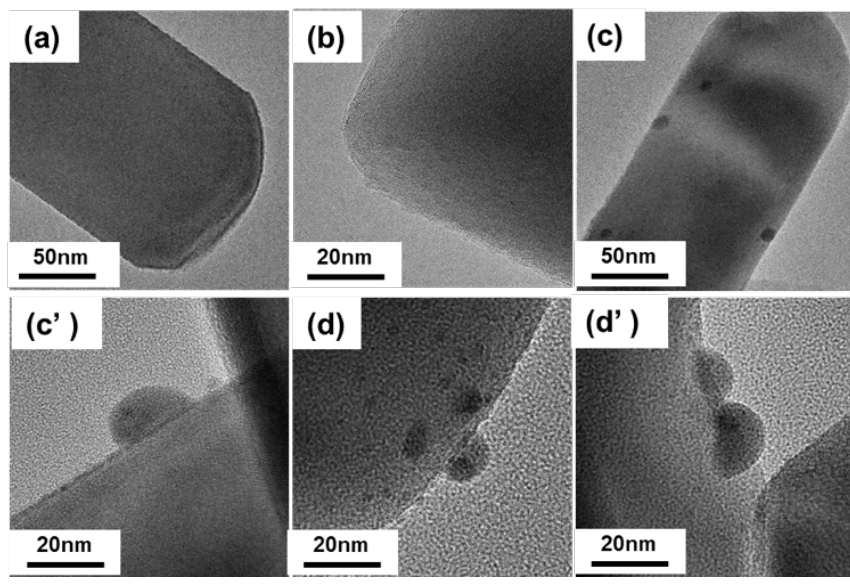

Fig. 4 TEM images of the prepared samples, (a) bare KTO, (b) $\mathrm{Mn}(0.15) / \mathrm{KTO}, \quad\left(\mathrm{c}, \mathrm{c}^{\prime}\right) \mathrm{Ag}(1.0) / \mathrm{KTO}$, and (d, d') $\mathrm{Ag}(1.0)-$ $\mathrm{Mn}(0.09) / \mathrm{KTO}$. 


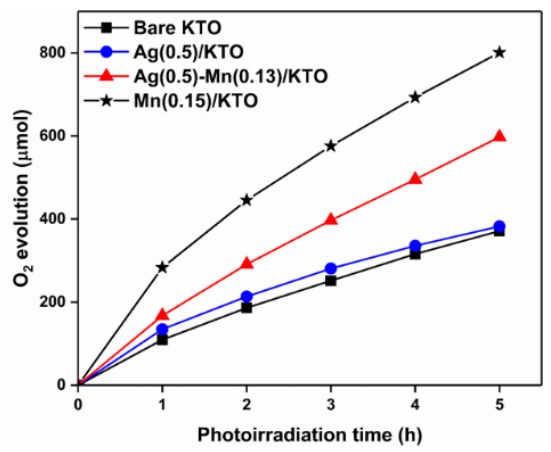

Fig. 5 Time course of $\mathrm{O}_{2}$ evolution over the prepared photocatalysts. Sacrificial reagents: $0.5 \mathrm{M}$ of $\mathrm{AgNO}_{3}$ solution. Light source: a $100 \mathrm{~W}$ high pressure $\mathrm{Hg}$ lamp.

In conclusion, it was found that the KTO sample loaded with both Ag metal and manganese oxide species such as $\mathrm{Ag}(0.5)-\mathrm{Mn}(0.13) / \mathrm{KTO}$ samples exhibited the highest activity $\left(10 \mu \mathrm{mol} \mathrm{h}^{-1}\right)$ and the highest selectivity $\left(S_{\mathrm{CO}}=98 \%\right)$ with the stoichiometric production ratio of the oxidative and reductive products, which showed almost 2 times higher $\mathrm{CO}$ productin rate than that of the $\mathrm{Ag}(1.0) / \mathrm{KTO}$ sample. The $\mathrm{MnO}_{x}$ cocatalyst can enhance the oxidative reaction, i.e., the $\mathrm{O}_{2}$ evolution (Eq. 1), which leads to the improvement of $\mathrm{CO}$ evolution (Eq. 2) with synergistic effect of Ag cocatalyst. Here, the dual cocatalyst, i.e., the combination of $\mathrm{Ag}$ and $\mathrm{MnO}_{x}$ species, simultaneously contribute to the reductive and oxidative reactions, respectively, realized the photocatalytic $\mathrm{CO}_{2}$ reduction to $\mathrm{CO}$ with a higher reaction rate and a higher selectivity such as $98 \%$.

$$
\begin{gathered}
\mathrm{H}_{2} \mathrm{O}+2 \mathrm{~h}^{+} \rightarrow \frac{1}{2} \mathrm{O}_{2}+2 \mathrm{H}^{+} \\
\mathrm{CO}_{2}+2 \mathrm{H}^{+}+2 \mathrm{e}^{-} \rightarrow \mathrm{CO}+\mathrm{H}_{2} \mathrm{O}
\end{gathered}
$$

This work was financially supported by Otsuka Chemical Co., Ltd, Hirose holdings \& Co., Ltd, the Kyoto University Foundation, and the Program for Elements Strategy Initiative for Catalysts and Batteries (ESICB), commissioned by the MEXT of Japan. XAFS experiments was approved by PF-PAC (2016G643).

\section{Conflicts of interest}

There are no conflicts to declare.

\section{Notes and references}

1 (a) M. Halmann, Nature, 1978, 275, 115; (b) O. Ishitani, C. Inoue, Y. Suzuki, T. Ibusuki, O. Ishitani, C. Inoue, Y. Suzuki and T. Ibusuki, J.Photoch. Photobio. A, 1993, 72, 269; (c) S. Sato, T. Arai, T. Morikawa, K. Uemura, T.M. Suzuki, H. Tanaka and T. Kajino, J. Am. Chem. Soc., 2011, 133, 15240; (d) S.N. Habisreutinger, L. Schmidt-Mende and J.K. Stolarczyk, Angew. Chem., Int. Ed., 2013, 52, 7372

2 K. lizuka, T. Wato, Y. Miseki, K. Saito and A. Kudo, J. Am. Chem. Soc., 2011, 133, 20863.

3 (a) M. Yamamoto, T. Yoshida, N. Yamamoto, H. Yoshida and S. Yagi, E-Journal Surf. Sci. Nanotechnol., 2014, 12, 299; (b) N. Yamamoto, T. Yoshida, S. Yagi, Z. Like, T. Mizutani, S. Ogawa, H. Nameki and H. Yoshida, E-Journal Surf. Sci. Nanotechnol., 2014,
12, 263; (c) H. Tatsumi, K. Teramura, Z. Huang, Z. Wang, H. Asakura, S. Hosokawa and T. Tanaka. Langmuir, 2017, 33, 13929.

4 Z. Wang, K. Teramura, S. Hosokawa and T. Tanaka, Appl. Catal. B Environ., 2015, 163, 241.

5 (a) T. Takayama, K. Tanabe, K. Saito, A. Iwase and A. Kudo, Phys. Chem. Chem. Phys., 2014, 16, 24417; (b) Z. Wang, K. Teramura, S. Hosokawa and T. Tanaka, Appl. Catal. B Environ., 2015, 163, 241; (c) H. Yoshida, L. Zhang, M. Sato, T. Morikawa, T. Kajino, T. Sekito, S. Matsumoto and H. Hirata, Catal. Today, 2015, 251, 132; (d) H. Yoshida, M. Sato, N. Fukuo, L. Zhang, T. Yoshida, Y. Yamamoto, T. Morikawa, T. Kajino, M. Sakano, T. Sekito, S. Matsumoto and H. Hirata, Catal. Taday, 2018, 303, 296.

6 (a) Z. Wang, K. Teramura, Z. Huang, S. Hosokawa, Y. Sakata and T. Tanaka, Catal. Sci. Technol., 2016, 6, 1025; (b) Z. Huang, K. Teramura, H. Asakura, S. Hosokawa and T. Tanaka, J. Mater. Chem. A., 2017, 5, 19351.

7 A. Anzai, N. Fukuo, A. Yamamoto and H. Yoshida, Catal. Commun., 2017, 100, 134.

8 R. Pang, K. Teramura, H. Asakura, S. Hosokawa and T. Tanaka, Appl. Catal. B Environ., 2017, 218, 770.

9 X. Zhu, A. Anzai, A. Yamamoto and H. Yoshida, Appl. Catal. B Environ., 2019, 243, 47.

10 (a) R.I. Bickley, F.S. Stone, J. Catal., 1973, 31, 389. (b) T. Berger, M. Sterrer, O. Diwald and E. Knozinger, ChemPhysChem, 2005, 6 ,2104; (c) Y. F. Li, Z. P. Liu, L. Liu and W. Gao, J. Am. Chem. Soc., 2010, 132, 13008; (d) R. Abe, J. Photochem. Photobiol. C Photochem. Rev., 2010, 11, 179; (e) A. Vojvodic and J.K. Norskov, Science, 2011, 334, 1355.

11 (a) A. Kudo and Y. Miseki, Chem. Soc. Rev., 2009, 38, 253; (b) J. Yang, D. Wang, H. Han and C. Li, Acc. Chem. Res., 2013, 46, 1900

12 Z. Chang, S. Huo, W. Zhang, J. Fang and H. Wang, J. Phys. Chem. C., 2017, 121, 11368.

13 Q. Zhai, S. Xie, W. Fan, Q. Zhang, Y. Wang, W. Deng and Y. Wang, Angew. Chem., Int. Ed., 2013, 52, 5776.

14 R. Pang, K. Teramura, H. Tatsumi, H. Asakura, S. Hosokawa and T. Tanaka, Chem. Commun., 2018, 54, 1053.

15 K. Maeda, A. Xiong, T. Yoshinaga, T. Ikeda, N. Sakamoto, T. Hisatomi, M. Takashima, D. Lu, M. Kanehara, T. Setoyama, T. Teranishi and K. Domen, Angew. Chem., Int. Ed., 2010, 49, 4096

16 J. Zhu, S. Pang, T. Dittrich, Y. Gao, W. Nie, J. Cui, R. Chen, H. An, F. Fan and C. Li, Nano Lett., 2017, 17, 6735.

17 Z. Jiang, D. Ding, L. Wang, Y. Zhang and L. Zan, Catal. Sci. Technol., 2017, 7, 3065.

18 (a) B. L. Wang, Q. Chen, J. Hu, H. Li, Y. F. Hu and L. M. Peng, Chem. Phys. Lett., 2005, 406, 95. (b) Q. Zhang, Y. Guo, K. Guo, T. Zhai and H. Li, Chem. Commun., 2006, 52, 6229.

19 K.Byrappa, S.Gali, B.M.R. Wanklyn, A.B.Kulkarni, S.K. Patil and G.Narendranath, J. Mater. Sci. Lett., 1990, 9, 898.

20 (a) K. Shimura, H. Kawai, T. Yoshida and H. Yoshida, ACS Catal., 2012, 2, 2126; (b) H. Yoshida, M. Takeuchi, M. Sato, L. Zhang and T. Teshima, Catal. Today, 2014, 232, 158; (c) P. Ponce-peña M. A. González-lozano, M. A. Escobedo-bretado and P. De Liragómez, Ceram. Int., 2015, 41, 10051; (d) L.F. Garay-Rodríguez, L.M.T. Martínez and E. Moctezuma, J. Energy Chem., 2019, 37, 18.

21 E. A. Davis and N. F. Mott, Philos. Mag., 1970, 22, 903. 
22 S. Xie, Y. Wang, Q. Zhang, W. Deng and Y. Wang, Chem. Commun., 2015, 51, 3430.

23 (a) R. Li, F. Zhang, D. Wang, J. Yang, M. Li, J. Zhu, X. Zhou, H. Han and C. Li, Nat. Commun., 2013, 4, 1432; (b) R. Li, H. Han, F. Zhang, D Wang and Can Li, Energy Environ. Sci., 2014, 7, 1369. 